\title{
The Challenges of Teaching and Learning Spirituality in Nursing
}

\section{Aru Narayanasamy}

University of Nottingham, United Kingdom

"Corresponding author: Aru Narayanasamy, Associate Professor, National Teaching Fellow, Academic Associate (HEA), Fellow of Higher Education Academy, Member of BACP Coaching Division, University of Nottingham, Faculty of Medicine \& Health Science, School of Health Sciences, Room 51, C Floor, Queens Medical Centre, Nottingham NG7 2HA, United Kingdom, Tel: +44 (0)115 823 0808; E-mailAru.Narayanasamy@nottingham.ac.uk

Received date: June 18, 2014, Accepted date: August 11, 2014, Published date: August 14, 2014

Copyright: (c) 2014 Narayanaswamy A. This is an open-access article distributed under the terms of the Creative Commons Attribution License, which permits unrestricted use, distribution, and reproduction in any medium, provided the original author and source are credited.

\section{Commentary}

The lexicon on spirituality and spiritual care is expanding in nursing and health care due to health care professionals concern about the dispirited person as consequence of illness. If spirituality is the essence of our being and it gives meaning and purpose to our very existence, then spiritual care is the greatest gift that health professionals could bring to those broken persons who have to navigate and negotiate through the terrains of personal catastrophes and suffering. Some consider that it is a real privilege to be part of the sufferer's journey and sometimes we find ourselves helping because of the compassion and connection we have with fellow humans. In furthering the epistemology of spirituality in nursing and health care, there is copious research and evidence-based literature to suggest that spirituality is good for the well-being of patients [1]. This holistic view draws our attention to spiritual needs. It is based on the premise that we all have needs and these are regarded as social, psychological, physical and spiritual [2]. It is postulated that a harmonious balance between the body, mind and spirituality is necessary for our wellbeing. Disturbance to any one of these dimensions leads to disharmony in the holistic well-being of an individual. Therefore, it is suggested that attention to the body, mind and spirit is likely to restore the holistic nature of the person. This is supported by Clark et al. who believe that a holistic view of healthcare is developing where emotional and spiritual needs are considered inextricably from physical and psychological needs [3].

Despite the claim in nursing about the importance of spirituality for our well-being there are debates and tensions about the reality of spirituality in health care, including the lack of consensus about what spirituality really means. Whilst acknowledging the controversies surrounding spirituality, including the lack of consensus about what spirituality really means, Chan makes a striking comment that spirituality refers to 'a family of different, yet connected meanings' in terms of meaning making in one's life [4]. However, if there is no consensus as what constitutes spirituality, then is it right to instigate its significance and application to patient care? It raises the question that if spirituality is elusive to definitions, then it is best not to dabble with it in clinical practice. The other contentious perspective is that spirituality is an invented notion, alluding to the point that there is no such thing as spirituality and therefore it is meaningless to both patients and clinical practice. In particular Paley, Henery and GilliatRay's have generated an extensive critique of spirituality in nursing on the grounds that it is a reification that is uncritically accepted in healthcare practice [5-7]. While these authors may have some justification in their discourses to be dismissive of the spirituality of nursing in the light of their observation, such assertions are misguided because extensive evidence amplifies its significance [1]. Discarding the notion of spirituality based on this questionable stance is no solution.
Nursing theorists maintain their stance that to be dismissive of spirituality in nursing tantamount to gross negligence of the very nature of the person. It matters because spirituality is a real and lived experience for many individuals (McSherry and Ross 2010). Indeed, Johnston Taylor calls for embedding of spirituality in everyday transaction and behaviour in clinical practice [2]. While there is mounting evidence about the positive effects of spirituality, it is less clear whether it is the nurse's sole responsibility to address all aspects of spirituality in health care practice as some studies suggest that many nurses lack competence in spiritual care due to impoverished nurse education in this area [1,4]. Advocates of spirituality highlight the potential of nurse education in addressing nurses' professional development in spirituality and spiritual care. However, it is doubtful whether nurses should be given the task of dealing with spirituality in practice without complete commitment to incorporate spirituality as a major curriculum component in nurse education. We also need to be cognisant of the fact that spirituality in wrong hands could be dangerous to patients' well being. In raising this concern, Narayanasamy (2010) poses the following [1]:

- If a patient's spirituality manifests as the need to resort to the occult and other darker sides should the nurse direct the patient to this as a way of meeting their needs?

- In regard to religious patients who request for prayers, should nurses pray and to whom?

- If the nurse or the patient do not share similar faith. Would nurses who are atheists be willing to pray?

- Where do we stand with regard to Shiatsu, Reiki, Shamanism and many more which are valid to some patients but shunned by some religions and faith groups.

Clearly these are some of the ethical issues and contentions that require attention and resolution to be found. Despite the reservations explored earlier, some support the idea that nurses should be educated to the level in which they are facilitated to be sensitive to patients' spirituality and able to detect whether patients are experiencing spiritual distress [8]. To strengthen spirituality in nursing, a multidisciplinary approach comprising theologians, social scientists, religious studies specialists, spirituality and pastoral care scholars and philosophers, to name a few, is the way forward to spirituality teaching and learning, where expert exposition of this subject is harnessed and transmitted. Having the benefit of multi-disciplinary approach to spirituality, nurse education is ideally placed where debates and tensions could be explored from multi-perspectives in the safe environment of the classroom. However, this cannot be done by quick fix solutions such as cookbook approaches derived from fact files on spirituality and religions/faiths and communication manuals as gestures of holistic care. Instead, skilful pedagogy on spirituality is required to manage the transition from abstract and complex theories of spirituality to practice. The pedagogy of spirituality can be 
Citation: Narayanasamy A (2014) The Challenges of Teaching and Learning Spirituality in Nursing. J Nurs Care 3: 189. doi: 10.4172/2167-1168.1000189

Page 2 of 2

challenging, messy, unpredictable, uncomfortable, chaotic, rocky, illogical, inflammatory and dark. This could done with sensitivity and tolerance to diverse and differing viewpoints involving various methods of teaching and learning, ranging from seminars, debates, educational games, scenario-based simulations and patients' narratives to bring reality to the classroom which foster student engagement. A multi-disciplinary and collaborative approach is the way forward to the challenges of teaching and learning spirituality in nursing.

\section{References}

1. Narayanasamy A (2010) Recognising spiritual needs

2. Johnston Taylor E (2007) What Do I Say? Talking with Patients about Spirituality. Philadelphia, PA: Templeton Foundation Press.
3. Clark PA, Drain M Malone MP (2003) Addressing patients emotional and spiritual needs. Joint Commission Journal on Quality and Safety 29 : $659-70$.

4. Chan MF (2009) Factors affecting nursing staff in practising spiritual care. Journal of Clinical Nursing, $19: 2128-2136$.

5. Paley $M$ (2008) Spirituality and nursing: A reductionist approach. Nursing Philosophy 9: 3-8.

6. Henery N (2003) Constructions of spirituality in contemporary nursing theory. Journal of Advanced Nursing, $42: 550-57$.

7. Gilliat-Ray S (2003) Nursing, professionalism and spirituality. Journal of Contemporary Religion 18: 335-350.

8. McSherry W, Ross L (2010) Spiritual Assessment in Health. Keswick: M\&K Publishers. 